\title{
Towards a more meaningful involvement of librarians in academic program reviews
}

Librarians in academic program reviews

Lynne Bowker

\author{
University of Ottawa, Ottawa, Canada
}

Received 24 October 2017

Revised 24 October 2017 Accepted 20 December 2017

\begin{abstract}
Purpose - Using a descriptive case study approach, this paper aims to validate academic librarians' perceptions that they are marginalized by faculty during academic program reviews, and recommends ways for the two groups to collaborate more effectively to make program reviews more meaningful.

Design/methodology/approach - The paper describes a case study at a Canadian university where the six types of documents produced as part of the program review process for ten graduate programs were analyzed using corpus analysis tools and techniques, such as keyword generation and key word in context analysis. For each program, documents were examined to determine the volume and nature of the discussion involving libraries in the self-study, library report annex, site visit itinerary, external reviewers' report, academic program's response and final assessment report.

Findings - The empirical evidence from the corpus analysis validates the findings of previous perceptionbased studies and confirms that librarians currently have a minor role in program reviews. Best practices and gaps emerged, prompting five recommendations for ways in which academic librarians can play a more meaningful role in the program review process.

Practical implications - The results suggest that programs are not currently putting their best foot forward during program reviews, but this could be improved by including librarians more fully in the program review process.

Originality/value - The present study contributes to the existing body of knowledge about the role of academic librarians in the program review process by providing direct and empirical measures to triangulate previous perception-based investigations that rely on surveys and interviews. It summarizes limitations of the current institutional quality assurance process and the benefits to be gained by involving librarians more in the process. It offers recommendations for policymakers and practitioners with regard to potential best practices for facilitating librarian involvement in academic program reviews.
\end{abstract}

Keywords Organizational culture, Quality assurance, Academic staff, Policy, Attitudes, Academic librarians

Paper type Case study

\section{Introduction}

Academic program review is a critical component of quality assurance (QA) in higher education; however, academic librarians report that their contributions to the review process

This study was funded by a 2016 Canadian Health Libraries Association Research Grant and an Insight Grant (435-2017-0075) from the Social Sciences and Humanities Research Council of Canada. We are grateful to Mike Scott, developer of the WordSmith Tools corpus analysis software package, for permission to use screenshots. As stated on the WordSmith Tools site, "For non profit-making academic use: No need to ask. You are hereby granted permission". (http://lexically.net/publications/ copyright_permission_for_screenshots.htm). Thanks are also due to the three University of Ottawa librarians who took the time to review and offer valuable feedback on an initial draft of this paper and its recommendations.

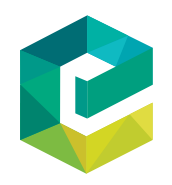

Quality Assurance in Education Vol. 26 No. 1, 2018 
QAE 26,1

are often minimal, and they suggest that faculty practices and attitudes are major barriers to their involvement. To date, investigations pertaining to librarians' participation in program reviews have been largely based on librarians' perceptions obtained through surveys or interviews. This study aims to validate or refute these perceptions by using an empirical corpus-based approach to investigate librarians' contributions to academic program reviews by analyzing the documents that are created as part of the review process. This investigation will take the form of a case study that focuses on the review documents that were produced during the cyclical program reviews for ten graduate programs in the health sciences at the University of Ottawa between 2011 and 2016. Furthermore, this research aims to identify both best practices and missed opportunities for meaningful collaboration between librarians and faculty members during program reviews, and to make recommendations for improving such collaborations moving forward.

This study is divided into six main sections. We begin with a brief description of the institutional quality assurance process at the University of Ottawa, followed by an overview of the literature that addresses the question of librarian involvement in program reviews. Next, we introduce the corpus analysis methods that were used to investigate a corpus of program review documentation for ten graduate programs in health-related fields. For each program's review, six different types of document were generated: the program's self-study, a library report, a site visit itinerary, the reviewers' report, the program response and a final assessment report. The results of the analyses of each document type are presented, followed by a more global discussion. The results of the analysis suggest that librarians are currently marginalized during the academic program review process, and that this is a missed opportunity for the university to enhance their programs and to promote the library's resources and services through the program review process. The paper ends with five recommendations for ways to integrate librarians more in the program review process for the benefit of all program stakeholders.

\section{Background and institutional context}

Countries around the world have recognized tho importance of quality assurance in higher education and have implemented processe academic program review (Tam, 1999; Brown, 2004; Mora, 2004; Shah et al., 2007). In Canada, public education falls under the mandate of the provincial governments, and in the province of Ontario, university quality assurance has gained increasing importance over the past 50 years (Goff, 2013). Initially focused largely on accountability, quality assurance has undergone a significant shift, with increasing emphasis now being placed on program enhancement (Harvey and Newton, 2007). As part of this new orientation, in 2010, each publicly assisted Ontario University developed its own Institutional Quality Assurance Process (IQAP). To secure academic standards and to ensure ongoing improvement, one of the components that must be part of the IQAP is a protocol for the review of new programs, as well as for the cyclical review of existing programs once every eight years.

As a member of the U-15 Group of Canadian Research Universities, the University of Ottawa is a research-intensive university, with over 185 graduate programs and more than 6,500 graduate students. The university's most recent strategic plan, "Destination 2020", identifies "research excellence" as one of its four strategic goals, noting that "Advances in knowledge and research go hand in hand with growth at the graduate studies level" (University of Ottawa, 2014a, p. 5). To support the goal of research excellence, the university will "continue to increase enrolment of top ranked graduate students, with a target of 16 per cent of our total student body by 2015, and 18 per cent by 2020" (University of Ottawa, 2014a, p. 6) and "build a world-class library and core facilities to support a world-class 
research university" (University of Ottawa, 2014a, p. 6). The university, therefore, clearly views strong connections between research excellence, graduate studies and library support. Moreover, as a publicly assisted university, the University of Ottawa has entered into a Strategic Mandate Agreement (SMA) with the Ontario provincial government. A major purpose of the SMA is to help guide future growth in universities by encouraging more focus on unique strengths. The University of Ottawa's SMA identifies seven areas of existing strength, as well as five areas that it will target for future growth. The area of "health" is listed as both an area of strength and one targeted for further development (University of Ottawa, 2014b, p. 13).

At the University of Ottawa, the graduate program review process begins with the drafting of a detailed self-study report prepared by the academic unit delivering the program. The self-study gives a comprehensive presentation of the program's objectives, learning outcomes, curriculum, admission criteria, faculty members, student body, governance and administration and resources and services, among other information. Once completed, a typical self-study report is approximately 80 to 100 pages in length, often with additional appendices. The self-study is then sent to three reviewers, who later come to the campus for a site visit where they meet with the various program stakeholders. The reviewers submit a report in which they identify the strengths and weaknesses of the program and also make recommendations for its enhancement. The academic program has an opportunity to respond to the reviewers' report. Finally, these three key documents the self-study, reviewers' report and program's response - are considered by the university's Graduate Program Evaluation Committee (GPEC). Following an analysis of these materials, the GPEC produces a fourth report known as the final assessment report, which contains a determination with regard to a program's quality, specifies any necessar 21 provements and reports the results back to the Ontario Universities Council on quality assurance.

Although the University of Ottawa's strategic plan underlined the importance of the library for supporting high quality research and graduate studies, the requirements set out in the institutional quality assurance plan (IQAP) regarding libraries are minimal. It is stated simply that the self-study must provide "Evidence that there are adequate resources to sustain graduate students' scholarship and research activities, including library support, information technology support and laboratory access" (University of Ottawa, 2011, section 6.1.3.5 c). Meanwhile, a search of the literature reveals that University of Ottawa is not unique in having minimally specified requirements for library contributions to program reviews (Salvesen, 2006).

\section{Librarian involvement in program reviews: a review of the literature}

Coates and Auld (2016) question whether methods used to evaluate postsecondary education in Canada are as effective as they could be. If we accept that academic libraries exist to improve the quality of studying and research, then academic librarians should be key players in assuring the quality of graduate programs and, by extension, in the graduate program review process. Nevertheless, many librarians report feeling marginalized in this process. For instance, Wu and Senior (2016) recently published the results of an extensive survey of academic business librarians in the USA, which sought to shed light on the role that these librarians play in the new program review process. Their findings reveal that many librarians perceive their participation to be "often a mere formality and an afterthought", noting that in the opinion of the librarians surveyed:

Most of the time, teaching faculty wait until the whole proposal is already crafted to contact the library. The implied expectation is for the librarian to provide an affirmative statement that "library resources are adequate" (Wu and Senior, 2016, p. 115).
Librarians in academic program reviews 
QAE

26,1

A main finding of the study is that "Although librarians feel strongly that they should be involved in the proposal process, they are unsure that the teaching faculty would share their opinion" (Wu and Senior, 2016, p. 120).

Overall, there have been few investigations into the nature of librarian participation in program reviews. While Costella et al. (2013) state that "library support has always been recognized to some extent in the assessment of academic programs and institutions", they go on to note that "involvement [of librarians] was often inconsistent and not well defined" (Costella et al., 2013, p. 16). Of particular interest are their observations that:

Although there is abundant evidence about why academic libraries need to accommodate institutional or accrediting body requirements, there is a paucity of literature that addresses the process through which libraries respond to these demands (Costella et al., 2013, p. 2).

And that "the literature offers considerably less evidence describing and operationalizing the role of academic libraries in institutional program review" (Costella et al., 2013, p. 5).

Of the few studies that have been conducted, most focus on the perspective of librarians, who often view faculty practices and attitudes as significant barriers to their participation. Gregory (1990) conducted an early investigation into the academic library's role in the new academic program proposal process in six different US states. Gregory argues that for any state level review process to be effective, a major consideration should be whether the library of the institution seeking to establish a new program has resources adequate to support the program in question. To investigate, Gregory conducts a qualitative study in which she first examines the criteria issued by the state review agencies to identify the issues associated with program review as it affects libraries. She follows this up with interviews (e.g. of library directors) to find out whether the libraries were involved in program reviews, what procedures were followed and, in their opinion, how successful was the procedure in terms of ensuring that effective library support was available for new programs. While she found that the level of participation of librarians in the new program review process varied, Gregory (1990, p. 134) noted that:

Substantial improvement in the procedures could be made in all of the states studied. [...] Otherwise, state-level program review takes on the character of a mere charade, conducted solely for the purpose of checking off all of the required boxes on the bureaucratic form.

Unfortunately, as reported by Wu and Senior (2016), the situation has not improved much in the past quarter century. Although more than 60 per cent of the 75 academic librarians who responded to their survey felt that librarians should play a part in the review process, over 65 per cent of respondents indicated that they were never involved (Wu and Senior, 2016, p. 119). In follow-up interviews with nine librarians, a common theme that emerged was that when librarians do try to participate actively in the review process, "anything from the library is considered pro forma and never really taken seriously" (Wu and Senior, 2016, p. 121). Meanwhile, in a similar vein, White (1999) surveyed academic business librarians to explore their perceptions on issues related to the professional accreditation process for business administration programs in the USA. Of the 77 respondents, only 7 per cent reported being very involved in the accreditation review process. Meanwhile, 27 per cent indicated that they had not been involved in the review process at all, and the explanation they gave was that they had not been invited to participate, or that their offer to do so was rejected by the academic unit.

Salvesen (2006) describes a new Norwegian body that oversees QA in higher education (NOKUT). She investigates "what role library services play in NOKUT's QA and accreditation systems-and not least, what role they could play" (Salvesen, 2006, n.p.) and 
concludes that library-related guidelines are outdated. For example, the criteria state that the institute must have a satisfactory academic library in the form of suitable locations with workplaces, modern technology and competent staff, as well as having easily accessible relevant digital and analogue collections and/or services for students and faculty. However, there is no focus on new services, such as digital institutional open-access publications, information literacy teaching or learning centers, which Salveson sees as a missed opportunity for promoting program quality. Nicholson et al. (2011) make similar observations about Ontario's Quality Assurance Framework, suggesting it is time to shift away from predominantly descriptive and collection-focused library reports to ones that use data to provide evidence of broader library support for quality scholarship (e.g. consultation, instruction and assistance services). Respondents to Mercer and Maciel's (2012) survey of 41 libraries that belong to the Association of Research Libraries (ARL) also felt that questions asked by accrediting agencies seem out of date with current service models.

Finally, a case study by librarians at the University of Western Ontario (UWO) (Costella et al., 2013) summarizes recent efforts made by the UWO library to involve librarians in the undergraduate program review process. The authors report that obtaining a seat for a librarian on the Senate Subcommittee for Undergraduate Program Review and developing a template for use by librarians when preparing material for the self-study have been two recently implemented initiatives. Membership on the subcommittee means that the library is aware of each program review as it arises. Meanwhile, the template is intended to help librarians by expediting the writing process, defining expectations about what should be in each review and promoting consistency of reports across disciplines. As these efforts are recent, the case study does not fully evaluate the initiatives taken but rather frames them as opportunities for academic librarians to work toward a more meaningful involvement in the review process.

Overall, the picture that emerges from the literature is one of a situation where there is considerable room for improved collaboration between faculty members and academic librarians as part of the program review process. However, this picture is presented mainly from the perspective of librarians. Moreover, it is based primarily on indirect evidence, such as surveys and interviews with librarians, who relay their perception that faculty attitudes are a major barrier to their participation. To our knowledge, this issue has not been investigated from the perspectives of other key players in the program review process, such as the academic unit, the reviewers or the program evaluation committee. If we are to see the full picture, we must investigate the situation from their perspectives also. Therefore, triangulation of data sources and methodology is desirable because it allows crossverification of data, and it makes it possible to capture different dimensions of a given phenomenon and thus contribute to a deeper understanding of the overall situation (Creswell and Plano Clark, 2010). Concretely, a more complete picture that is based on both direct and indirect measures, and which considers multiple stakeholder perspectives, would serve as a solid base from which to identify best practices and missed opportunities for librarian participation in the program review process. This, in turn, will lead to recommendations of ways to meaningfully involve academic librarians in program reviews with a view to enhancing graduate program quality and research for the benefit of the entire university community.

\section{Method}

This project uses a corpus-based methodology. In this section, we begin by presenting the contents of the corpus before going on to describe the corpus analysis tool that was used and the steps that were taken to investigate the corpus contents.
Librarians in academic program reviews 
QAE

26,1

6

Table I.

Health-related graduate programs at the University of Ottawa that have completed a cyclical program review between 2011 and 2016 as part of the recently implemented institutional quality assurance process
At the University of Ottawa, the Faculty of Health Sciences (FHS) currently delivers nine programs at the graduate level, while the Faculty of Medicine (FM) delivers five graduate programs. Additionally, the Telfer School of Management (TSM) offers two graduate programs with a strong health-related component. Given its identification of "health" as an area of strength and development, the University of Ottawa has a vested interest in assuring that the quality of these graduate programs remains high. Since the new institutional quality assurance process was introduced in 2011, ten of the university's health-related graduate programs have completed a cyclical program review, as summarized in Table I. The program review documentation for these ten programs will form the corpus for the present study.

For each of the ten graduate programs in a health-related field, six key pieces of program review documentation were examined:

(1) self-study prepared by the academic program (i.e. faculty, staff and students);

(2) library report prepared by an academic librarian and included as an appendix to the self-study;

(3) itinerary for the site visit by external reviewers;

(4) reviewers' report prepared by faculty members who are disciplinary experts from outside the university;

(5) academic program's response to the reviewers' report; and

(6) final assessment report produced by the university's GPEC and submitted to the Ontario Universities Council on Quality Assurance.

The documents in the corpus were examined with the help of corpus analysis software known as WordSmith Tools (Scott, 2017). Two basic types of analysis were conducted: qualitative analyses, such as examining sections of the documents that discuss libraryrelated issues to identify themes, and quantitative analyses, such as calculating the total percentage of each document that was devoted to discussing library topics.

One feature of WordSmith is the concordancer, which permits users to search for and display Key Words in Context (KWIC). A sample of a KWIC display can be seen in Figure 1. To identify sections of the documents that contained discussions of library-related topics, we began by using the search terms librar* and biblioth*[1]. Next, we examined the retrieved occurrences of these words in their surrounding context (e.g. sentences or paragraphs) to identify other LIS terms that were being used as part of these discussions. Examples of additional terms that were identified include: audiovisual resources, collection, databases, indexes, journals, libguide, library catalogue, literature search, reference desk, research

\begin{tabular}{ll}
\hline Faculty & Program \\
\hline Faculty of Health Sciences (FHS) & MSc, PhD in Human Kinetics \\
& MSc, PhD in Nursing \\
Faculty of Medicine (FM) & MSD in Population Health \\
& MSc, PhD in Biochemistry \\
& MSc, PhD in Epidemiand Molecular \\
& MSc, PhD in Microbiology and Immunology \\
Telfer School of Management (TSM) & MSc, PhD in Neuroscience \\
& Master of Health Administration \\
& MSc in Health Systems \\
\hline
\end{tabular}


articles and Scopus. Several other libraries in the region, to which students and faculty at the University of Ottawa have access, were also mentioned (e.g. Carleton University Library, Library and Archives Canada, the National Science Library and Ottawa Public Library). Using these search terms, further searches were conducted to retrieve additional contexts, and within these contexts, more new LIS terms were identified. We continued examining the documents in this iterative fashion until we felt confident that we had identified all the sections of each document that contained a discussion of library-related issues. Next, we calculated the percentage of each document that was devoted to these library discussions. This was done by first determining each document's total word count, and then counting the number of words in the sentences/paragraphs about libraries and expressing this as a percentage of the overall content.

WordSmith can also be used to carry out other types of statistical analyses, such as measures of "keyness". Although raw frequency can be a potential indicator of a term's importance in a text, it is not sufficient as a sole measure of identifying the importance of a subject within a text. In addition to a frequency count, WordSmith can calculate the keyness of a given term. Scott and Tribble (2006, p. 55) describe keywords as "items of unusual frequency in comparison with a reference corpus". To identify keywords, WordSmith compares the contents of a particular text (e.g. a self-study) against a much larger reference corpus (e.g. a newspaper corpus) to identify those words in the text that are unusually frequent as compared to their frequency in the reference corpus. In other words, keyness is a measure of the frequency of disproportionate occurrence. It also important to note that keyness is a textual feature, not a language feature, which means that a word has keyness in a certain textual context, but this same word may not have keyness in other contexts. We generated a list of keywords for each self-study, reviewers' report and final assessment report in our program review corpus and then examined these lists to see if any libraryrelated terms appeared.

\section{Results}

In this section, we will summarize and discuss our findings for each of the six program review document types, before proceeding to a more global discussion. The categories of documents are discussed in the order in which they are generated as part of the University of Ottawa's graduate program review process outlined above: self-studies, library reports, site visit itineraries, external reviewers' reports, academic program responses and final assessment reports.
Librarians in academic program reviews

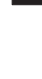

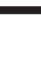

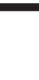




\section{QAE}

26,1

Table II.

The word count and percentage of each self-study that discusses library issues

\section{Self-studies}

As noted above, the first step in the graduate program review process is the preparation of a detailed self-study by the academic unit. At the University of Ottawa, a basic template is provided to guide the initial development of the self-study. However, in recognition of the fact that graduate programs across the institution may differ significantly from one another, customization of the template is permitted, and thus, stakeholders have considerably flexibility in presenting their program. Once completed, the main body of a self-study report is usually around 80 to 100 pages in length, and additional material may be appended.

As presented in Table II[2], for each of the ten self-study documents, we calculated the total number of words, as well as the number of words found in sections that discussed library topics. We can see that the length of the self-studies varies considerably, with the shortest being just under 20,000 words and the longest being over twice that length, at nearly 45,000 words. However, as summarized in Table II, the percentage of the content that focuses on library-related matters in each of these documents is very small: less than 1 per cent in seven of the ten self-studies, and averaging just 0.54 per cent across all these documents. In addition, none of the lists of keywords generated for the ten self-studies contain any library-related terms, whatsoever.

Each of the ten self-studies contains a section entitled "Library", which is a section that appears in the template provided by the university's quality assurance office. Four of the self-studies have just a single paragraph in this section, which consists primarily of an invitation for readers to consult the appended library report. Four other self-studies contain two paragraphs in this section, and the remaining two include three paragraphs about the library. In total, there are 32 additional references to library-related topics scattered throughout other sections of the 10 self-studies, with 5 being the highest number of additional references appearing in any one self-study. Overall, discussions of the library are not well-integrated into or woven throughout the broader description of an academic program as part of the self-studies; most mentions of the library outside of the "library" section consist of a single sentence or a cross-reference back to that section or to the appendix containing the library report. Moreover, when the library is discussed, it is typically with regard to its physical resources - catalogue, collection, databases, indexes, journals, libguides, research articles and study carrels - and only rarely do these discussions touch on librarians or library services, such as workshops or reference services.

\begin{tabular}{lccc}
\hline Program & $\begin{array}{c}\text { Total word } \\
\text { count }\end{array}$ & $\begin{array}{c}\text { Word count of discussions } \\
\text { about libraries }\end{array}$ & $\begin{array}{c}\text { Percentage of self-study } \\
\text { focusing on libraries }\end{array}$ \\
\hline Human kinetics & 39,304 & 213 & 0.54 \\
Nursing & 23,765 & 193 & 0.81 \\
Population health & 25,312 & 176 & 0.7 \\
Biochemistry & 28,524 & 170 & 0.6 \\
Cellular and molecular medicine & 44,798 & 172 & 0.38 \\
Epidemiology & 27,795 & 289 & 1.04 \\
Microbiology and immunology & 26,417 & 103 & 0.39 \\
Neuroscience & 27,765 & 104 & 0.37 \\
Health administration & 19,858 & 402 & 2.02 \\
Health systems & 22,369 & 376 & 1.68 \\
Average & 28,591 & 220 & 0.54
\end{tabular}




\section{Library reports}

The library reports are authored by academic librarians and are appended to the self-study documents. The university's quality assurance office does not provide a template for the library report, but the library team has prepared one. Again, however, there is scope for customization. The ten library reports included in this study were prepared by four different T3 librarians, and as the data in Table III indicate, some librarians provide much more detail than others: the shortest report is under 2,000 words, while the longest is more than three times that length, with the average length of a library report being slightly less than 3,000

Librarians in academic program reviews words.

In examining the content of the library reports in more detail, we can see that some librarians, such as Librarian C, repurposed large chunks of text, cutting and pasting generic material from one report to the next. Meanwhile, Librarian B tailored the reports to a greater degree, adding more program-specific information. In all cases, we see that descriptions of library services are given greater attention in the library reports than they are in the selfstudies, the latter of which focus primarily on the library's physical resources.

\section{Itineraries}

Each graduate program evaluation requires a site visit by external reviewers who are experts in the subject area covered by program. The typical duration of a site visit is two business days. The itineraries for the ten site visits were examined to determine whether the external reviewers toured the library or met with a librarian, and if so, for what length of time. The results are summarized in Table IV.

In reviewing the itineraries, we can see that three of the ten site visits did not feature any library tour or librarian meeting, whatsoever, while the remaining seven did include some kind of direct contact with the library, which typically ranged from 30 to 45 min in length. However, in two of these cases, the library was just one stop on a relatively brief tour that also included visits to other facilities. Moreover, as part of these multi-facility tours, the reviewers did not actually meet with librarians. Meanwhile, only five of the ten itineraries specified that the reviewers actually had a meeting with a subject librarian. This means that in half of the program review site visits, the reviewers received information about the library from someone other than a librarian, if at all.

\begin{tabular}{lcc}
\hline Program & $\begin{array}{c}\text { Total word count of library } \\
\text { report (appended to self-study) }\end{array}$ & Librarian who prepared report \\
\hline Human kinetics & 3,905 & Librarian A \\
Nursing & 6,320 & Librarian B \\
Population health & 5,149 & Librarian B \\
Biochemistry & 1,929 & Librarian C \\
Cellular and molecular medicine & 1,919 & Librarian C \\
Epidemiology & 2,284 & Librarian B \\
Microbiology and immunology & 1,937 & Librarian C \\
Neuroscience & 1,901 & Librarian C \\
Health administration & 2,355 & Librarian D \\
Health systems & 1,953 & Librarian D \\
Average & 2,965 & \\
\hline
\end{tabular}

Table III. Word count and authorship of library report appendices 


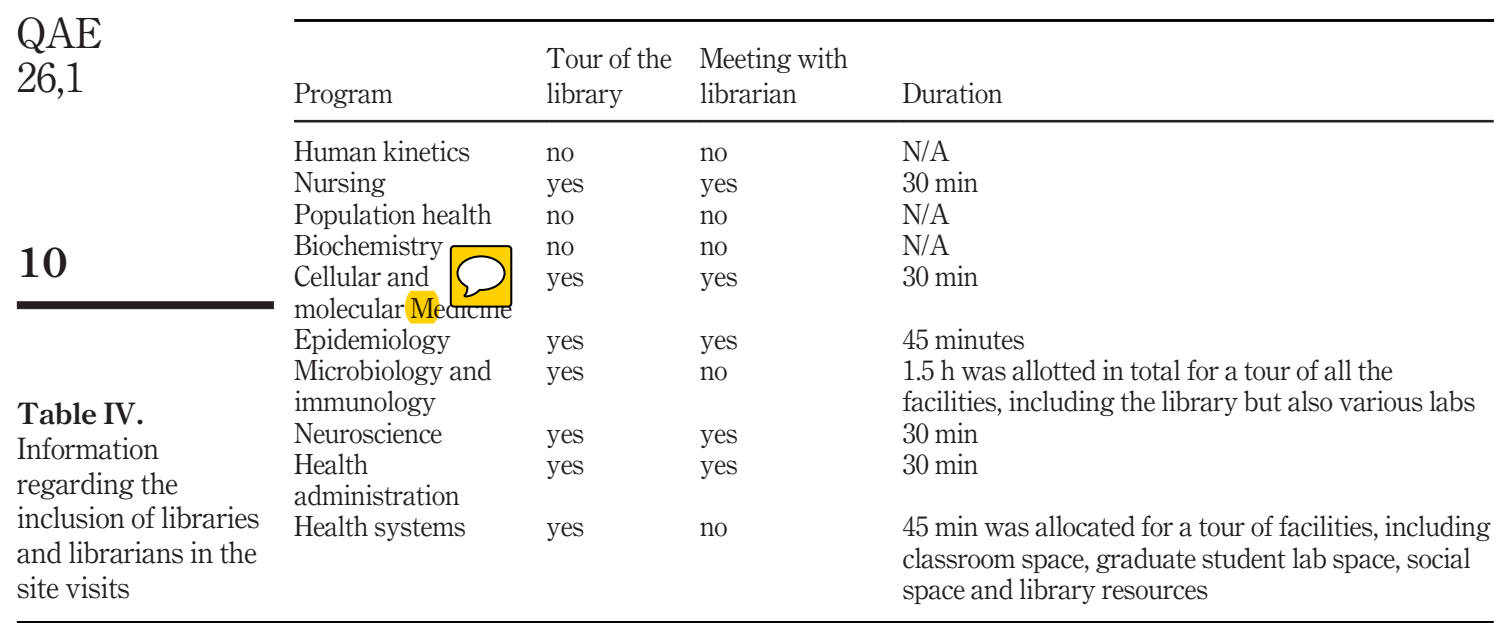

\section{Reviewers' reports}

Following the site visit, the reviewers collectively prepare a report in which they share their observations about the strengths and weaknesses of the program and make recommendations for program improvement. Reviewers' are not obliged to follow a template but are asked to keep in mind at least the following four points when conducting their evaluation and preparing their report:

(1) Does the program have the resources necessary to deliver a good quality program and offer a positive student experience?

(2) Does the program make sense within the overall context of the discipline and will the program's graduates meet disciplinary expectations?

(3) Does the program have any particular strengths or distinctive characteristics?

(4) Does the program have a reasonable and adequate plan to address any perceived shortcomings?

As summarized in Table V, for each of the ten reviewers' reports, we calculated the total number of words in the report, as well as the number of words found in sections that discussed library topics. The reviewers' reports range in length from a little more than 3,000 words to just over 7,500 words, with an average length of 4,921 words. Of the ten reports, eight contain at least some mention of libraries. On average, the percentage of the reviewers' reports that are devoted to discussing library issues is just under 1 per cent. Once again, none of the lists of keywords generated for the reviewers' reports contain any library-related terms, whatsoever.

In examining the reports, it is clear that some reviewers' comments on the perceived adequacy or insufficiency of the library resources and services are based on their reading of the self-study and/or discussions with faculty or students, and not on a discussion with a librarian. In four of the reviewers' reports, the library was mentioned only briefly with a remark to the effect that no concerns had been raised by the program stakeholders with regard to the library collection or services. Meanwhile, in three other reports, reviewers relayed a specific concern. In the first two cases, the reviewers appear to be merely passing on comments made by students and faculty. One of these is a request for some additional discipline-specific journals, and the other is a request for additional subject librarians in health sciences. However, in the third case, 
the reviewers' comment appears to be based on their own direct observation of speaking with students after first having spoken with a librarian:

Students were not aware of all the services that were available at the library (e.g. training in the use of databases, building comprehensive literature searches and maintaining bibliographies).

Of these specific concerns, reviewers considered the latter two to be serious enough to warrant making specific recommendations in their report. These recommendations are, respectively, to hire an additional health sciences librarian and to promote library services more effectively to graduate students and their supervisors.

Meanwhile, in three of the reports, the reviewers draw specific attention to positive aspects of library services, based on their own observations made during a meeting with a librarian. However, no positive comments about the library were made by reviewers who did not meet with a librarian. Excerpts of positive comments recorded in the reviewers' reports include the following:

- "The library is superbly organized and has recognized the challenges and opportunities posed and offered by the digital age. It is well-designed, well-equipped with meeting rooms, discussion areas and study carrels".

- "Touring the library facilities to which the students have access was a highlight of the reviewers' visit. The Health Sciences Librarian is a tremendous resource for the graduate students in this program. The level of support she provides to students is truly outstanding; a wonderful model to be emulated by other programs".

- "The services offered by the library (instituted by the head librarian and delivered by the research librarian) were very impressive. Students are mentored in literature searches, in the preparation of bibliographies and even in the organization of an effective Journal Club. For the latter, once a research topic is chosen for the term, the research librarian will work with the students to generate the most appropriate weekly searches for the top papers on the subject".

\section{Program responses}

Following receipt of the report from the reviewers, the academic program has an opportunity to respond to the reviewers' report. As presented in Table VI, we have calculated both the length of the ten program response documents and the percentage of each document devoted

\begin{tabular}{|c|c|c|c|c|}
\hline Program & $\begin{array}{l}\text { Total word } \\
\text { count }\end{array}$ & $\begin{array}{c}\text { Word count of discussions } \\
\text { about libraries }\end{array}$ & $\begin{array}{l}\text { Percentage of reviewers' } \\
\text { report focusing on libraries }\end{array}$ & \\
\hline Human kinetics & 5,449 & 36 & 0.66 & \\
\hline Nursing & 7,174 & 103 & 1.44 & \\
\hline Population health & 7,642 & 0 & 0 & \\
\hline Biochemistry & 3,900 & 0 & 0 & \\
\hline Cellular and molecular medicine & 4,529 & 111 & 2.45 & Table V. \\
\hline Epidemiology & 6,608 & 82 & 1.24 & The word count and \\
\hline Microbiology and immunology & 3,248 & 29 & 0.89 & The word count and \\
\hline Neuroscience & 3,619 & 75 & 2.07 & percentage of each \\
\hline Health administration & 3,099 & 15 & 0.48 & reviewers' report that \\
\hline Health systems & 3,942 & 14 & 0.36 & discusses library \\
\hline Average & 4,921 & 47 & 0.96 & issues \\
\hline
\end{tabular}

Librarians in academic program reviews 


\begin{tabular}{llccc} 
QAE & Program & $\begin{array}{c}\text { Total word count of } \\
\text { program response }\end{array}$ & $\begin{array}{c}\text { Word count of discussions } \\
\text { about libraries }\end{array}$ & $\begin{array}{c}\text { Percentage of program } \\
\text { response focusing on libraries }\end{array}$ \\
\cline { 2 - 5 } & $\begin{array}{l}\text { Human kinetics } \\
\text { Nursing }\end{array}$ & 2,870 & 0 & 0 \\
& $\begin{array}{l}\text { Population health } \\
\text { Biochemistry }\end{array}$ & 2,476 & 69 & 0.92 \\
$\mathbf{1 2}$ & Cellular and & 2,977 & 0 & 0 \\
& molecular medicine & 7,865 & 0 & 0 \\
Table VI. & Epidemiology & 691 & 186 & 2.36 \\
The word count and & Microbiology and & & 0 & 0 \\
percentage of each & immunology & 1,131 & 0 & 0 \\
program response & Neuroscience & 1,378 & 0 & 0 \\
that discusses library & Health administration & 2,819 & 14 & 0.5 \\
issues & Health systems & 2,028 & 0 & 0 \\
& Average & 3,206 & 27 & 0.38 \\
\hline
\end{tabular}

to discussing library-related issues. We can see rather dramatic differences in the lengths of the program responses, with the shortest being just under 700 words, and the longest being more than ten times that length.

In examining the response documents, it is clear that the programs focus the vast majority of their efforts on responding to specific concerns or areas for improvement that have been identified by the reviewers. Therefore, given that only three specific libraryrelated concerns were raised in the reviewers' reports, it is perhaps not surprising that only three of the program responses address library issues, and these discussions consists mainly of describing how the program proposes to rectify the observed shortcomings.

\section{Final assessment reports}

The final assessment reports are produced by the members of the GPEC - which is composed primarily of faculty members from across the university - after they have taken into consideration the self-study, the reviewers' report and the program's response. The final assessment report contains just three sections: program strengths, areas for program enhancement and specific recommendations for improvement (which include timelines and an indication of which authorities will oversee the implementation of the recommendations). As noted above, this document, which culminates the internal review process, is later sent to the provincial quality assurance council. As illustrated in Table VII, there is variation in the length of the final assessment reports, but the average length is approximately 1,000 words. Although some mention of libraries appeared in each of the five previous document types, none of the final assessment reports contain any mention of library-related topics, whether as strengths or as areas needing improvement.

\section{Discussion}

The preceding results give a clear indication that, with the exception of the library report appendices, none of the documents associated with academic program reviews in the health sciences place much emphasis on library-related issues. For instance, when WordSmith's keyword generator was applied to the self-studies, the reviewers' reports, program responses and final assessment reports, not a single term on the resulting lists of keywords was related to libraries. The groups responsible for authoring each of each of these types of report consist primarily of academic faculty, and this lends support to observations made by 
researchers such as Wu and Senior (2016), who note that librarians are given the impression by faculty members that library-related issues are not central to program reviews.

Meanwhile, an analysis of the KWIC contexts reveals that there is a notable difference in the way that the self-studies and the library reports present libraries. In the self-studies, the limited discussions of library-related issues that do exist focus on physical resources catalogue, collection, databases, indexes, journals, libguides, research articles and study carrels - and only rarely do these discussions touch on librarians or library services, such as workshops or reference services. In contrast, the library reports not only offer a detailed description of the pertinent part of the collection and other resources but also provide rich details about services offered by library staff in support of teaching and research. These findings support observations made by Salvesen (2006) and Nicholson et al. (2011), who go on to argue that predominantly collection-focused descriptions of the library are insufficient, and that evidence of broader library support for quality scholarship should be incorporated into the program review documentation. In addition, this difference in the way that libraries are presented in the two documents is indicative of two related underlying problems: it suggests that the self-study authors may not be fully aware of or appreciate the range of services available through the library, which, in turn, suggests that librarians are not actively included as members of the team responsible for drafting the self-study document, but rather, they are merely called upon to supply an appendix.

It is concerning that the information about library services is found primarily in the appendix because readers may not consult it in depth given that material in an appendix is typically considered to be supplementary and not essential. The relegation of detailed library-related information to an appendix lends weight to the observations made by $\mathrm{Wu}$ and Senior (2016, p. 115), for example, suggesting that librarians are included in program reviews only as an afterthought. By discussing library services primarily in the appendix, rather than in the main body of the self-study, the importance and visibility of these services are minimized, and programs miss out on opportunities to draw attention to how the library might support the learning objectives of the program or to promote value-added services that enhance their programs and the experiences of their students and faculty.

Not including librarians on the site visit schedules represents another missed opportunity for programs to put their best foot forward. Only half of the site visits included a meeting with a librarian on the itinerary. This is in line with the findings of both White (1999) an 1 and Senior (2016), who reported that 27 and 65 per cent of academic librarians $Q$ onded to their respective surveys indicate that they have never been invited by the academic unit to participate in a program review. In our study, this would seem to

\begin{tabular}{lcc}
\hline Program & Total word count of FAR & Word count of discussions about libraries \\
\hline Human kinetics & 1,532 & 0 \\
Nursing & 1,309 & 0 \\
Population health & 1,479 & 0 \\
Biochemistry & 875 & 0 \\
Cellular and molecular medicine & 713 & 0 \\
Epidemiology & 927 & 0 \\
Microbiology and immunology & 768 & 0 \\
Neuroscience & 843 & 0 \\
Health administration & 663 & 0 \\
Health systems & 1,311 & 0 \\
Average & 1,042 & \\
\hline
\end{tabular}

Librarians in academic program reviews
The total word count and number of words that discuss library issues in each final assessment report 
QAE 26,1

represent a missed opportunity because in those instances where reviewers did meet with librarians, this meeting clearly made a very positive impact and resulted in comments based on the reviewers' own direct observations rather than based on second-hand comments made by faculty or students. Excerpts from the reviewers' reports such as "superbly organized", "tremendous resource for graduate students", "outstanding level of support", "wonderful model", "impressive services", "very informative", (ning "highlight of the reviewers' visit" would seem to confirm that allocating even 30 min uru of a two-day visit to meet with a librarian will generate a positive impression of the program which will be favorably recorded in the reviewers' report. It is also worth noting that the reviewers who met with librarians tend to place more emphasis on the library services, rather than on the physical resources, in their reports. This provides further encouragement for incorporating descriptions of key library services into the body of the self-study, rather than consigning this information to the appendix.

Globally, the data in this study reveal a trend of diminishing visibility for the library over the course of the program evaluation process. While 100 per cent of the self-studies make at least some reference to library issues and include a library report as an appendix, just 70 per cent of the itineraries include a library tour or meeting with a librarian, and only 80 per cent of the reviewers comment on the library in their reports. Meanwhile, a mere 30 per cent of the program responses address library-related topics. Finally, there is no mention of libraries - positively or negatively - in the final assessment reports, even though reviewers' had both offered enthusiastic praise of some library services and made some specific recommendations for extending and raising the visibility of these services. However, instead of the library's visibility being raised, the opposite seems to happen: throughout the academic program review, librarians and libraries gradually move from being mere appendages in the first stage of the process to becoming invisible by the end of it. This situation would seem to support a need to take action in a manner similar to that described by Costella et al. (2013) at the University of Western Ontario, where inviting a librarian to sit on the institution's program evaluation committee helped to give librarians a voice, and, in turn, to increase the recognition of their current and potential role in the program review process.

\section{Conclusions and recommendations}

In the library and information science literature, the notion that academic librarians are marginalized in the academic program review process has emerged as an axiom: something that is largely assumed to be true, but the evidence for which is based primarily on the perceptions of librarians themselves. Little objective data regarding the behavior of other stakeholders in the program review process is available. The present study used corpusbased methods to study program review documentation to obtain some objective measures of librarian involvement in program reviews. Although this is a small-scale study based on just ten graduate program reviews conducted at a single institution, the results do support the findings from previous perception-based studies where librarians express their feelings that faculty practices and attitudes are barriers to their involvement in program reviews.

\section{The corpus-based findings support the previous perception-based studies that}

- teams that draft self-studies are composed of faculty and do not include librarians;

- services provided by librarians are largely unacknowledged outside of the appendices; 
- library tours and meetings with librarians are not systematically scheduled as part of a site visit;

- comments made by reviewers (i.e. faculty from other universities) about the adequacy or insufficiency of library matters are sometimes based on second-hand information received from faculty and students rather than on first-hand observations;

Librarians in academic program reviews

- program responses, which are prepared by faculty members, focus almost exclusively on addressing perceived library-related deficiencies and do not call attention to strengths observed by the reviewers; and

- program evaluation committee members, who are faculty, do not appear to select library-related questions for recognition as either strengths or areas for improvement in the final assessment reports.

Even though this is a small sample, some best practices have emerged, such as formally scheduling a meeting with a librarian as part of the site visit. In this study, the most detailed and positive comments about libraries, including comments about services as well as resources, appeared in the reports submitted by reviewers who had had the opportunity to meet with library staff. Conversely, in those instances where reviewers did not meet with librarians, the reports contained almost no comments about the library, and the few comments that did appear were exclusively focused on library resources and were extremely bri? basis of the findings, best practices and missed opportunities that have been identified through this study, we have drawn up five recommendations that can help faculty members and academic librarians to work together meaningfully to present a more comprehensive and accurate description of library support for graduate programs, and to maintain an ongoing dialogue with regard to continuous program improvement. Additionally, we suggest that as departmental chairs or program directors are usually responsible for managing key elements of the review process - such as identifying the team members who will lead the development of the self-study, prepare the itinerary or coordinate the response to the reviewers' report - these chairs or directors are well-positioned to help champion a more prominent role for librarians in the program review process. In this capacity, a chair or director could seek to ensure that all participants have a clear and common understanding of the markers of success for the library during a program review so that everyone is on the same page as to what is important and what ought to be reported. A number of the recommendations below can contribute to addressing this issue. The following five recommendations were initially shared with three university librarians, who offered support for the recommendations, as well as suggestions for refinement, which have been incorporated.

(1) Include a librarian on the team that develops the self-study.

Although faculty appear to be somewhat comfortable discussing aspects of the library's collection, it is important to note that physical resources are necessary but not sufficient for ensuring a positive student experience and training highly qualified personnel to become productive members of the research community. Including librarians on the team that develops the self-study will ensure that not only the collection, but also the library's value-added services, are emphasized as part of the program presentation and are promoted to program stakeholders.

(2) Incorporate discussions of library resources and services in pertinent places throughout the self-study. 


\section{QAE}

26,1

\section{6}

Once a librarian has been welcomed to the self-study development team, he or she can identify areas of the self-study where discussions of services and resources can be properly contextualized instead of being discussed only in a dedicated section - or appendix - where they are presented out of context. Integrating pertinent highlights from a supporting appendix into the body of the report will facilitate on-point messaging and right-time marketing of the library's contributions to the students' experience and preparation. Overall, an integrated presentation will be more effective and have a greater impact on the reviewers, and it will serve as an opportunity to raise faculty and student awareness of all that the library has to offer.

(3) Ensure that a meeting with a librarian is scheduled as a part of the site visit.

Librarians can do a better job than faculty members when it comes to explaining how the library supports the program and its student learning outcomes. Programs should use their strongest resources at the right moments in the review process. The findings of the present study suggest that a (minimum) 30-min meeting with a librarian is time well spent for the reviewers, so it is in a program's best interests to ensure that such a meeting is built into the itinerary. In addition, librarians should be made aware of the review criteria or of any issues that the reviewers are interested in learning more about, so that they can make the most of the meeting time available.

(4) Include a librarian as a resource person on the program evaluation committee.

A program evaluation committee may be composed of both faculty members, who have voting privileges, and resource staff, who can provide various types of specialized knowledge. Resource personnel on the University of Ottawa's program evaluation committee currently include the quality assurance coordinator, as well as a curriculum design specialist from the Centre for University Teaching; however, no librarian sits on this committee. It would be beneficial for the program evaluation committee to have access to a resource person who is knowledgeable about the library's role and contributions to graduate programs, and who could help to raise the visibility of these contributions and to suggest ways in which the library could further enhance graduate programs.

(5) Share the results of the program evaluation with librarians.

Librarians are not currently viewed as members of the self-study development team, academic unit or program evaluation committee. As such, there is no clear mechanism for informing librarians about the results of the program evaluation at any stage. It is discouraging for anyone to work hard toward a goal, such as supporting graduate education, and to receive no feedback about the positive effects, misplaced efforts or existing gaps related to these efforts. Librarians should be informed of the feedback received by the reviewers, as well as the results of the final assessment report. By including librarians in the feedback loop, academic programs can build stronger relations with librarians, and the librarians will, in turn, feel more motivated and better able to provide enhanced and targeted support for the programs. The resulting virtuous cycle will benefit all stakeholders in the program and will help librarians to realize a role as full partners in the research and teaching enterprise. It may even produce a ripple effect generating additional as-yet-unknown benefits for relations between faculty and librarians.

To sum up, the goal of this study was to determine whether librarians' perceptions that they are marginalized during the program review process could be validated through objective evidence obtained through a corpus-based investigation of academic program 
review documents. The results confirm that librarians are not meaningfully involved in academic program reviews, and that this represents a missed opportunity for universities to put their best foot forward. This investigation was limited in that it considered only ten graduate programs in health-related fields at a single institution. However, the programs are managed by three different faculties (i.e. health sciences, medicine and management), each with its own distinct culture, and the patterns observed cross all three. The case study produced informative results which suggest that it could be worth extending this study to include other programs and institutions. It is hoped that the discussion and recommendations provided in this paper will serve to advance the discussion about the contributions of academic librarians - both actual and potential - to the academic program review process.

\section{Notes}

1. Note that because the University of Ottawa is an officially bilingual university, where both English and French have equal status as working languages, some of the documents were produced in English, some in French and some in a mixture of both languages. Searches were, therefore, carried out in both languages.

2. Owing to the very small values for the library discussions, it was difficult to display this information graphically without using a log-based scale, which can be challenging to read. We, therefore, chose to present the information in tabular format.

\section{References}

Brown, R. (2004), Quality Assurance in Higher Education: The UK Experience since 1992, Routledge, London.

Coates, K. and Auld, D. (2016), "We need a better system to grade postsecondary schools", The Globe and Mail, 14 September, available at: www.theglobeandmail.com/opinion/we-need-a-bettersystem-to-grade-postsecondary-schools/article31875099/

Costella, J. Adam, T. Gray, F. Nolan, N. and Wilkins, C. (2013), "Undergraduate program review processes: a case study in opportunity for academic libraries", Western Libraries Publications, Paper 36, available at: http://ir.lib.uwo.ca/wlpub/36

Goff, L. (2013), "Quality Assurance Requirements in Ontario Universities: How did we get here?”, in Kompf, M. and Denicolo, P.M. (Eds ), Critical Issues in Higher Education, Sense Publications, Rotterdam, pp. 97-114.

Gregory, V.L. (1990), "The academic library in the program review process", Collection Management, Vol. 12 Nos 3/4, pp. 125-134.

Harvey, L. and Newton, J. (2007), “Transforming quality: moving on”, in Westerheijden, D., Stensaker, B. and Rosa, M.J. (Eds), Quality Assurance in Higher Education: Trends in Regulation, Translation and Transformation, Springer, Dordrecht, pp. 225-245.

Mercer, H. and Maciel, M. (2012), SPEC Kit 330: Library Contribution to Accreditation, Association of Research Libraries, Washington, DC, available at: http:/publications.arl.org/LibraryContribution-to-Accreditation-SPEC-Kit-330/

Mora, J.G. (2004), "A Decade of Quality Assurance in Spanish Universities", in Schwarz, S. and Westerheijden, D.F. (Eds), Accreditation and Evaluation in the European Higher Education Area, Kluwer Academic Publishers, Dordrecht, pp. 421-443.

Nicholson, K., Thomas, D. and Stephenson, C. (2011), "QAF, UUDLEs and GDLEs: What Ontario's New Quality Assurance Framework means for academic librarians" Ontario Library Association Super Conference, available at: http://works.bepress.com/karen_nicholson/15/ 
QAE 26,1

Salvesen, H. (2006), "The quality assurance system for higher education in Norway - with particular reference to the library services", LIBER Quarterly, Vol. 16 Nos 3/4, available at: http://doi.org/ $10.18352 / \mathrm{lq} .7862$

Scott, M. (2017), "WordSmith Tools version 7, Stroud, Lexical Analysis Software”, available at: http:// lexically.net/wordsmith/index.html

Scott, M. and Tribble, C. (2006), Textual Patterns: Key Words and Corpus Analysis in Language Education, John Benjamins, Amsterdam/Philadelphia.

Tam, M. (1999), "Quality assurance policies in higher education in Hong Kong”, Journal of Higher Education Policy and Management, Vol. 12 No. 2, pp. 215-226.

University of Ottawa (2011), "Institutional Quality Assurance Process (IQAP)", available at: www.uottawa. ca/graduate-studies/sites/www.uottawa.ca.graduate-studies/files/uo_iqapgraduatestudies_final_ version_june_27_2011.pdf

University of Ottawa (2014a), "Destination 2020: The University of Ottawa's Strategic Plan", available at: www.uottawa.ca/about/sites/www.uottawa.ca.about/files/destination-2020-strategic-plan.pdf

University of Ottawa (2014b), "Strategic Mandate Agreement", available at: www.tcu.gov.on.ca/pepg/ publications/vision/OttawaAgreement.pdf

White, G.W. (1999), "Managing the accreditation process: a survey of academic business librarians", Library Management, Vol. 20 No. 8, pp. 431-438.

Wu, K. and Senior, H. (2016), "Business librarians and new academic program review", Journal of Business and Finance Librarianship, Vol. 21 No. 2, pp. 114-134.

\section{Further reading}

Shah, M., Nair, S. and Wilson, M. (2011), "Quality Assurance in Australian Higher Education: Historical and Future Development”, Asia Pacific Education Review, Vol. 12 No. 3, pp. 475-483.

\section{Corresponding author}

Lynne Bowker can be contacted at: lbowker@uottawa.ca

For instructions on how to order reprints of this article, please visit our website: www.emeraldgrouppublishing.com/licensing/reprints.htm Or contact us for further details: permissions@emeraldinsight.com 


\section{AUTHOR QUERIES}

\section{AUTHOR PLEASE ANSWER ALL QUERIES}

AQau-Please confirm the given-names and surnames are identified properly by the coloun

=Given-Name, $\mathbf{a}=$ Surname

The colours are for proofing purposes only. The colours will not appear online or in print.

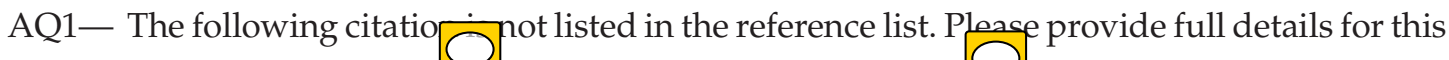
citation: Shah et al., 2007, Jeswell and Plano Clark (2010). 